\title{
Hyperglycemic diet and training alter insulin sensitivity, intramyocellular lipid content but not UCP3 protein expression in rat skeletal muscles
}

\author{
MORAD VAISY ${ }^{1 *}$, KAROLINA SZLUFCIK $^{1 *}$, MICHAEL MARIS $^{1 *}$, KATRIEN DE BOCK $^{1}$, \\ MATTHIJS K.C. HESSELINK ${ }^{2}$, BERT O. EIJNDE ${ }^{1}$, PATRICK SCHRAUWEN ${ }^{3}$ and PETER HESPEL ${ }^{1}$ \\ ${ }^{1}$ Department of Biomedical Kinesiology, Faculty of Kinesiology and Rehabilitation Sciences, Research Centre for \\ Exercise and Health, K.U. Leuven, Tervuursevest 101, B-3001 Leuven, Belgium; Departments of \\ ${ }^{2}$ Human Movement Sciences; ${ }^{3}$ Human Biology, Nutrim School for Nutrition, Toxicology and \\ Metabolism, P.O. Box 616, 6200 MD Maastricht, The Netherlands
}

Received December 17, 2009; Accepted February 8, 2010

DOI: 10.3892/ijmm_00000421

\begin{abstract}
Intramyocellular lipids (IMCL) and mitochondrial uncoupling protein-3 (UCP3) have been implicated in the development of muscular insulin resistance. This study aimed to investigate the role of IMCL and UCP3 in the development of glucose intolerance and muscular insulin resistance during 12 weeks of an obesity-inducing 'cafeteria-style' diet alone $(\mathrm{CAF})$, or in conjunction with exercise training from weeks 8-12 $\left(\mathrm{CAF}_{\mathrm{TR}}\right)$, in rats. At the end of the intervention period, gain in body weight was $20 \%$ higher in CAF $(305 \pm 10 \mathrm{~g})$ than controls $(\mathrm{CON})(255 \pm 14 \mathrm{~g} ; \mathrm{p}<0.001)$ and $\mathrm{CAF}_{\mathrm{TR}}(253 \pm 7 \mathrm{~g}$; $\mathrm{p}<0.001)$. Furthermore, compared with $\mathrm{CON}$, the Matsuda insulin sensitivity index (ISI), assessed during a 2-h intravenous glucose tolerance test, was markedly lower in CAF $(6.7 \pm 0.4)$ than in either $\mathrm{CON}(15.6 \pm 1.4 ; \mathrm{p}<0.001)$ or $\mathrm{CAF}_{\mathrm{TR}}(11.2 \pm 1.1$; $\mathrm{p}<0.001)$. Moreover, in CAF glucose transport at a submaximal insulin concentration $(200 \mu \mathrm{U} / \mathrm{ml})$ was reduced by $\sim 60 \%$ $(\mathrm{p}<0.05)$ in both red and white gastrocnemius muscles, but not in $\mathrm{m}$. soleus. However, glucose transport in $\mathrm{CAF}_{\mathrm{TR}}$ was similar to $\mathrm{CON}$ in red gastrocnemius. In CAF fiber-specific IMCL content determined in $\mathrm{m}$. soleus and extensor digitorum longus (EDL), was higher than in $\mathrm{CON}(\mathrm{p}<0.01)$ and $\mathrm{CAF}_{\mathrm{TR}}$ $(\mathrm{p}<0.001)$. Muscle UCP3 protein content was not changed by any of the interventions. Interestingly, within CAF and $\mathrm{CAF}_{\mathrm{TR}}$, ISI closely negatively correlated with IMCL content in both type I (soleus, r=-0.93; EDL, r=-0.90; $\mathrm{p}<0.05$ ) and IIa $(\mathrm{EDL}, \mathrm{r}=-0.52, \mathrm{p}<0.05)$ muscle fibers. These findings indicate that changes in IMCL content but not UCP3 content are
\end{abstract}

Correspondence to: Dr Peter Hespel, Research Centre for Exercise and Health, FaBeR-K.U. Leuven, Tervuursevest 101, B-3001 Leuven, Belgium

E-mail: peter.hespel@faber.kuleuven.be

*Contributed equally

Key words: fatty acids, carbohydrates, muscular insulin resistance implicated in short-term effects of cafeteria-style diet and exercise training on muscular insulin sensitivity in rats.

\section{Introduction}

It is well established that environmental factors such as unhealthy diet and sedentary lifestyle are important causes of insulin resistance. Skeletal musculature largely accounts for postprandial peripheral glucose disposal (1) and it is well documented that a hypercaloric diet, and particularly exaggerated energy intake in the form of saturated fatty acids and/or high-glycemic index carbohydrates, can impair insulin sensitivity in skeletal muscles (2). Furthermore, physical inactivity promotes the development of insulin resistance, whilst exercise training clearly improves muscular insulin sensitivity (3). Still, the precise mechanisms by which diet and exercise interact to modulate insulin action in muscle cells are incompletely understood. In this regard, one line of evidence clearly indicates that deficient oxidative fat metabolism in muscle cells is implicated in the etiology of muscular insulin resistance. Studies have shown that conditions, where fatty acid delivery to muscle cells exceeds the potential for intracellular fat oxidation, cause intramyocellular lipid (IMCL) accumulation together with deficient insulin action. Thus, close negative correlations have been found between the degree of peripheral insulin sensitivity and IMCL content in both healthy subjects and in humans or rats afflicted with insulin resistance, as well as in patients with type II diabetes and their offspring (4-6). Furthermore, acute lipid challenge due to either fatty acid infusion or a fat-rich diet caused IMCL to substantially increase, while insulin sensitivity decreased (7). Most recently, a study in obese rats demonstrated that upregulation of fatty acid transport in excess of the capacity for intracellular fat oxidation, probably is the primary mechanism responsible for an increased rate of triacylglycerol accumulation (8). However, the precise mechanisms linking lipid accumulation to deficient insulin action in muscle cells remain unclear. A direct causal relationship between IMCL accumulation and insulin sensitivity seems unlikely because in endurance-trained subjects, enhanced insulin sensitivity typically exists against the background of 
elevated IMCL content (9). This so-called 'athlete's paradox' is related to the higher rate of oxidative fat turnover for energy provision occurring in muscles of physically active individuals both during and after exercise $(10,11)$. Indeed, a high turnover rate of IMCL is considered to inhibit accumulation of toxic fatty acid metabolites such as diacylglycerol (DAG), peroxidised fatty acids and ceramides, which are supposed to interfere with insulin signaling $(9,12-14)$. Along this line, some of us have previously hypothesized that uncoupling protein-3 (UCP3), a mitochondrial anion carrier protein which is highly expressed in muscle cells, acts as a mitochondrial export protein for fatty acid anions and/or lipid peroxides, and via this mechanism it prevents mitochondrial oxidative damage and resulting deterioration of insulin efficiency (15-18). Support for such hypothesis comes from studies showing that the UCP3 gene expression is consistently upregulated in various conditions of stimulated energy provision by fat oxidation (16,19-25). Accordingly, insulin-resistant individuals already in a pre-diabetic state exhibit abnormal oxidative damage in muscle cells, as well as elevated intramitochondrial FFA accumulation together with lower UCP3 protein content (26-28). Furthermore, a recent study using targeted metabolomics in both mice and cultured myotubes revealed a strong connection between skeletal muscle insulin resistance and lipid-induced mitochondrial stress due to excessive B-oxidation (29).

Against this background, we investigated the interaction of exercise and diet in regulating whole-body glucose tolerance and muscular insulin sensitivity, and the relationship with IMCL content and muscle UCP3 protein expression. We used an obesity-inducing highly palatable cafeteria-style diet, containing a very high fraction of high-glycemic index carbohydrates, to induce glucose intolerance and peripheral insulin resistance in rats (30). Such diet also markedly enhances fat supply to skeletal muscles by sucrose-induced stimulation of hepatic lipogenesis (31). We speculated that the detrimental effects of cafeteria-style diet on whole body glucose tolerance and muscular insulin sensitivity are associated with elevated IMCL and UCP3 content in muscles, and that these effects are reversed by exercise training.

\section{Materials and methods}

Animals. Male Wistar rats, weighing 200-225 g, were obtained from the K.U. Leuven Animal Breeding Centre. Rats were housed in individual cages and maintained on a constant lightdark cycle $(12: 12 \mathrm{~h})$ at $22^{\circ} \mathrm{C}$. Rats were given ad libitum access to food and water. Study protocol was approved by the Animal Ethics Committee of K.U. Leuven.

Study protocol. Rats were randomly assigned to three experimental groups receiving different dietary and exercise interventions during a 12 -week period. Group 1 (CON) served as a control group and received a normal rodent pellet diet (Muracon-G, Carfil Quality, Oud-Turnhout, Belgium) throughout the study. Group 2 (CAF) was fed a so-called 'cafeteria-style' diet (30) which was prepared from powdered rodent pellets (Muracon-G, Carfil Quality, Oud-Turnhout, Belgium; $330 \mathrm{~g} / \mathrm{kg}$ ), full fat sweetened condensed milk (Nestlé, Vevey, Switzerland; $330 \mathrm{~g} / \mathrm{kg})$, sucrose $(70 \mathrm{~g} / \mathrm{kg})$, and water $(270 \mathrm{~g} / \mathrm{kg})$. The detailed composition of the two diets is given
Table I. Energy composition of the control and 'cafeteria-style' diet.

\begin{tabular}{lcc}
\hline & Control diet & 'Cafeteria-style' diet \\
\hline Total carbohydrate & & \\
Starch & $55 \%$ & $21 \%$ \\
Sugars & $8 \%$ & $48 \%$ \\
Total fat & & \\
Saturated FFA & $3 \%$ & $8 \%$ \\
Unsaturated FFA & $9 \%$ & $8 \%$ \\
Total protein & $25 \%$ & $15 \%$ \\
\hline
\end{tabular}

Energy content (\% total kcal) of fat, carbohydrates and protein of the control and cafeteria diets is given.

in Table I. Group $3\left(\mathrm{CAF}_{\mathrm{TR}}\right)$ also received a cafeteria-style diet but in addition was subjected to exercise training $(1 \mathrm{~h}$ swimming, 5 times per week in water maintained at $32-35^{\circ} \mathrm{C}$ ) during the last 4 weeks of the intervention period. To ensure continuous swimming a load equivalent to $2 \%$ of body weight was attached to the tail. Rats were provided with an excess (40-60 g) of ample freshly prepared cafeteria food or normal pellets every morning, and daily food intake was calculated by weighing the residual food the next morning. At the end of the 12-week intervention period and after an overnight fasting, an intravenous glucose tolerance test (IVGTT) was performed. Rats were then allowed to recover from IVGTT and received their diet for 4 more days. Following an overnight fast, hind limb perfusions were performed to assess muscle glucose transport and evaluate the direct effects of palmitate and glucose on muscle UCP3 mRNA content.

IVGTT. Rats were anaesthetized by an intraperitoneal injection ( $0.2 \mathrm{ml} / 100 \mathrm{~g}$ body weight) of a mixture containing $50 \%$ ketalar (50 mg/ml ketamine, Pfizer, Brussels, Belgium), 25\% Rompun $^{\circledR}$ (2\% xylazine, Bayer, Leverkussen, Germany) and $25 \%$ atropine $(0.5 \mathrm{mg} / \mathrm{ml})$, and prepared surgically for an IVGTT. This involved catheter insertion into the left jugular vein. Subsequently, after an overnight fast (16-18 h) conscious rats were injected with $1 \mathrm{~g}$ glucose $/ \mathrm{kg}$ body weight using a $30 \%(\mathrm{w} / \mathrm{v})$ glucose solution in $0.9 \%(\mathrm{w} / \mathrm{v})$ saline. For blood glucose determination, tail vein blood samples $(25 \mu \mathrm{l})$ were collected in Na-heparinsed capillaries before glucose injection and 5, 10, 15, 30, 60, 90 and 120 min afterwards. Blood glucose concentration was immediately measured using an automated glucose analyzer (Analox GM7, London, England). Additionally, tail vein blood $(150 \mu \mathrm{l})$ was collected for plasma insulin determination at 0, 10, 30 and 90 min. Plasma insulin was assayed by a sensitive rat insulin RIA kit (Linco research, MO, USA). Area under the curve (AUC) for insulin and glucose, fasted insulinogenic index [(fasted insulin)/fasted (glucose)] and Matsuda Insulin Sensitivity index (ISI) (32) were calculated.

Rat hind limb perfusions. To evaluate the effects of cafeteriastyle diet and training on muscle glucose transport, at the end of the 12-week intervention period and after an overnight fast, rats were anaesthetized by an intraperitoneal injection of 
pentobarbital sodium (5 mg/100 g body weight) and were prepared surgically for hindquarter perfusion as previously described (33). The effect of cafeteria-style diet on muscle glucose transport was evaluated in cell-free hind limb perfusions. The initial perfusate $\left(500 \mathrm{ml}\right.$ at $\left.35^{\circ} \mathrm{C}\right)$ consisted of Krebs-Ringer bicarbonate buffer solution, $4 \%$ bovine serum albumin (fraction V, Sigma-Aldrich, St. Louis, MO, USA), $0.15 \mathrm{mM}$ pyruvate, $4.2 \mathrm{IU} / \mathrm{ml}$ heparin, and 0 or $200 \mu \mathrm{U} / \mathrm{ml}$ insulin. During the perfusion the arterial perfusate was continuously gassed with a mixture of $95 \% \mathrm{O}_{2}$ and $5 \% \mathrm{CO}_{2}$ yielding average $\mathrm{pO}_{2}$ and $\mathrm{pH} 630 \pm 13$ and $7.33 \pm 0.02 \mathrm{mmHg}$, respectively. Following surgical preparation, hind limbs were allowed to recover for 15 min with perfusate recirculation at a rate of $20 \mathrm{ml} / \mathrm{min}$. The initial $150 \mathrm{ml}$ of glucose-free perfusate passing through the hindquarter were discarded. Hereafter, the perfusate was replaced by a new perfusion mix containing 8 $\mathrm{mM}$ 2-deoxy-D-glucose, $1 \mathrm{mM}$ mannitol, as well as 2-deoxyD-2,6 $\left[{ }^{3} \mathrm{H}\right]$ glucose (Amersham Radiochemicals, GE Healthcare, Uppsala, Sweden; specific activity $51.0 \mathrm{mCi} / \mathrm{mmol} / \mathrm{l}$ ) and D-1-[14 C]mannitol (Amersham Radiochemicals; specific activity $87.0 \mathrm{mCi} / \mathrm{mmol} / \mathrm{l})$ yielding constant perfusate activities of $0.075 \mu \mathrm{Ci} / \mathrm{ml}$ for ${ }^{3} \mathrm{H}$ and $0.05 \mu \mathrm{C} / \mathrm{ml}$ for ${ }^{14} \mathrm{C}$ during a 10-min one-way perfusion at a flow of $20 \mathrm{ml} / \mathrm{min}$. Immediately after, the white medial superficial part of the gastrocnemius muscle (white gastrocnemius, GW), the red deep proximal and medial portion of gastrocnemius (red gastrocnemius, GR), as well as the extensor digitorum longus (EDL) and soleus muscles were dissected from both hind limbs, freed from visible connective tissue and blood, snap frozen with aluminium clamps cooled in liquid nitrogen and stored at $-80^{\circ} \mathrm{C}$ for further biochemical analysis. Muscle samples, for later histochemical analysis, were first mounted in embedding medium (Tissue-Tek, Sakura FineTek, Zoeterwoude, The Netherlands) cooled in isopentane and then stored at $-80^{\circ} \mathrm{C}$.

Measurement of muscle glucose transport was performed using muscle perchloric acid extracts and applying correction for ${ }^{3} \mathrm{H}$ for label in the extracellular space as determined by the ${ }^{14} \mathrm{C}$ counts for mannitol, as previously described in detail (34). To study the direct effect of palmitate and glucose on muscle UCP3 mRNA expression, separate hind limb perfusion experiments were performed in control rats weighing 200$225 \mathrm{~g}$. Procedures were largely similar to the perfusions for assay of muscle glucose transport. However, to facilitate hind limb oxygenation during these longer perfusion experiments $(\sim 3 \mathrm{~h})$, erythrocytes were added to the perfusion mix. The initial perfusate $\left(300 \mathrm{ml}\right.$ at $\left.37^{\circ} \mathrm{C}\right)$ consisted of Krebs-Henseleit solution, 1-3-day-old washed bovine erythrocytes at a hematocrit of $30 \%$ and $5 \%$ bovine serum albumin (Cohn Fraction V, Sigma-Aldrich, St. Louis, MO, USA), $100 \mu \mathrm{U} / \mathrm{ml}$ insulin, $0.15 \mathrm{mM}$ pyruvate, $7.6 \mathrm{mM}$ bicarbonate and 0.3 $0.5 \mathrm{mM}$ lactate originating from erythrocytes. After discarding the first $25 \mathrm{ml}$ of perfusate that passed through the hindquarter, the perfusate was recirculated at a flow of $12.5 \mathrm{ml} / \mathrm{min}$. After a 15 min equilibration period, the left soleus and GW were taken and used as control. Subsequently, the common iliac vessels supplying the left hind limb were tied off and a clamp was fixed tightly around the proximal part of the leg. Perfusion to the right leg was then continued for $150 \mathrm{~min}$ at a reduced flow of $9 \mathrm{ml} / \mathrm{min}$, which resulted in similar perfusion pressures as for bilateral perfusion at a flow of $12.5 \mathrm{ml} / \mathrm{min}$. At the end of perfusion muscle samples (soleus and GW) were collected from the right leg following identical procedures as for the left leg. Perfusion pressures and flow rates were measured at regular intervals. Different experimental conditions were created by adding high physiological concentrations of palmitate $(2 \mathrm{mM})$, or glucose $(10 \mathrm{mM})$, or both, to the perfusion mix. It was previously shown that $2 \mathrm{mM}$ total palmitate concentration, which corresponds to $15 \mathrm{nM}$ palmitate not bound to albumin (35), results in maximal rate of palmitate uptake in perfused rat muscles (36). Furthermore, a group of control rats was perfused in the absence of added glucose or palmitate. Perfusions were carried out in a randomized order. Palmitate was first solubilised in $1 \mathrm{M} \mathrm{NaOH}$ and $0.9 \% \mathrm{NaCl}$, where after it was added to albumin solution heated to $45^{\circ} \mathrm{C}$.

Fiber typing and Oil-Red-O staining. Serial sections $(4 \mu \mathrm{m})$ from soleus and EDL muscles were laid together on uncoated glass slides. Fiber type-dependent staining for the intramyocellular lipid content (IMCL) was carried out using the Oil-Red-O (ORO) technique as previously described in detail (37). Briefly, cryosections were fixed for $10 \mathrm{~min}$ in $0.1 \%$ Triton X-100 added to $4 \%$ paraformaldehyde in phosphatebuffered saline (PBS). Slides were rinsed with wash buffer (0.5\% BSA in PBS), blocked with $10 \mathrm{mM} \mathrm{NH}_{4} \mathrm{Cl}$ for $30 \mathrm{~min}$ and washed again. Slides were prehybridised in $1 \%$ BSA in PBS for $30 \mathrm{~min}$. Thereafter, sections were incubated overnight at $4^{\circ} \mathrm{C}$ with primary monoclonal antibodies against human myosin heavy chain I (A4.840 supernatant, Developmental Studies Hybridoma Bank at the University of Iowa, IA, USA) and IIa (N2.261 supernatant, Developmental Studies Hybridoma Bank) to determine muscle fiber type (I and IIa, respectively). The incubation was followed by bathing with wash buffer, after which conjugated antibodies (type I, FITC antimouse IgM, Southern Biotechnology Associates, Birmingham, AL, USA type IIa, Alexa Fluor350 antimouse IgG1, Molecular Probes, Leiden, The Netherlands) were supplied. Slides were then washed with wash buffer, incubated in $10 \%$ formalin neutral buffer, washed again with deionised water and finally stained for $15 \mathrm{~min}$ by the ORO working solution. ORO stock solution was prepared by adding $0.5 \mathrm{~g}$ ORO (Sigma-Aldrich, St. Louis, MO, USA) to $100 \mathrm{ml}$ Isopropyl alcohol (99\%). Thereafter slides were washed one more time with deionised water before coverslips were mounted with fluorescent mounting medium (DakoCytomation, Carpinteria, CA, USA). Slides were examined using a Nikon E1000 fluorescence microscope (Nikon, Boerhavedorm, Germany) using a Texas red excitation filter for ORO, and FITC and DAPI filters for type I and IIa muscle fibers, respectively. Fiber type-specific IMCL content was expressed as the percentage of fiber area covered by stained fat droplets and the mean values were used for data analysis.

Western blotting. Frozen sample from soleus and EDL (30$40 \mathrm{mg}$ ) were homogenized in $400 \mu 1$ lysis buffer (50 mM Hepes pH 7.5, $150 \mathrm{mM} \mathrm{NaCl}, 20 \mathrm{mM} \mathrm{Na}{ }_{4} \mathrm{P}_{2} \mathrm{O}_{7}, 20 \mathrm{mM}$ ß-glycerophosphate, $10 \mathrm{mM} \mathrm{NaF}, 2 \mathrm{mM}$ EDTA, $1 \mathrm{mM} \mathrm{MgCl} 2,1 \mathrm{mM}$ $\mathrm{CaCl}_{2}, 2 \mathrm{mM} \mathrm{Na}_{3} \mathrm{VO}_{4}, 1 \%$ (v/v) Igepal, $10 \%$ (v/v) glycerol and 1 tablet/10 ml Protease Inhibitor Cocktail Tablets, EDTA-free (Roche Applied Science, Basel, Switzerland). After incubation 
Table II. Dietary analysis of food intake in control rats and rats receiving a 'cafeteria-style' diet in the absence (CAF) or presence of exercise training $\left(\mathrm{CAF}_{\mathrm{TR}}\right)$.

\begin{tabular}{lccc}
\hline & $\mathrm{CON}$ & $\mathrm{CAF}$ & $\mathrm{CAF}_{\mathrm{TR}}$ \\
\hline $\begin{array}{l}\text { Energy intake } \\
\text { (kcal/day) }\end{array}$ & $83.1 \pm 1.2$ & $93.4 \pm 1.6^{*}$ & $86.5 \pm 1.1^{\dagger}$ \\
$\begin{array}{l}\text { Fats (g/day) } \\
\quad \text { Unsaturated }\end{array}$ & $0.82 \pm 0.01$ & $0.80 \pm 0.01$ & $0.74 \pm 0.01^{* \dagger}$ \\
$\quad \begin{array}{l}\text { Saturated } \\
\text { Proteins }\end{array}$ & $0.28 \pm 0.01$ & $0.88 \pm 0.02^{*}$ & $0.82 \pm 0.01^{* \dagger}$ \\
(g/day) & $5.25 \pm 0.08$ & $3.41 \pm 0.06^{*}$ & $3.16 \pm 0.04^{* \dagger}$ \\
Carbohydrates (g/day) & & \\
$\quad$ Sugar & $1.72 \pm 0.02$ & $11.2 \pm 0.20^{*}$ & $10.4 \pm 0.13^{* \dagger}$ \\
Starch & $11.3 \pm 0.16$ & $4.92 \pm 0.09^{*}$ & $4.56 \pm 0.06^{* \dagger}$ \\
\hline
\end{tabular}

Values are means \pm SE for control rats $(\mathrm{CON}, \mathrm{n}=10)$, rats in the absence (CAF, $n=16)$ and presence of exercise training $\left(\mathrm{CAF}_{\mathrm{TR}}\right.$, $\mathrm{n}=15)$. CON was maintained on a normal rodent diet for 12 weeks, whilst $\mathrm{CAF}$ and $\mathrm{CAF}_{\mathrm{TR}}$ rats received a 'cafeteria-style' diet. $\mathrm{CAF}_{\mathrm{TR}}$ also underwent an exercise training program during the final 4 weeks of the dietary intervention period. See Materials and methods for further details. ${ }^{*} \mathrm{p}<0.05$ versus $\mathrm{CON},{ }^{\dagger} \mathrm{p}<0.05$ versus $\mathrm{CAF}$.

at $4^{\circ} \mathrm{C}$ for $30 \mathrm{~min}$, samples were centrifuged $\left(4^{\circ} \mathrm{C}, 60 \mathrm{~min}\right.$, $13,000 \mathrm{x} \mathrm{g})$ and the supernatant was stored at $-80^{\circ} \mathrm{C}$. Total protein concentration was determined using the BCA (bicinchoninic acid) Protein Assay Kit (Thermo Fisher Scientific, Waltham, MA, USA). UCP3 protein level was determined as previously described (38) and expressed as arbitrary units (A.U.). Briefly, $20 \mu \mathrm{g}$ of total protein was separated using SDS-gel electrophoresis. After electrophoretic transfer UCP3 protein was detected using a rabbit polyclonal UCP3 antibody (code 1331; kindly provided by L.J. Slieker and Eli Lilly).

Real-time $q P C R$. Total RNA from frozen muscle samples was extracted using an ABI Prism 6100 Nucleic Acid Prepstation (Applied Biosystems, Nieuwerkerker a/d IJssel, The Netherlands) and contaminated DNA was removed using DNase (Applied Biosystems). Total RNA was reverse transcribed using the High Capacity cDNA Archive Kit (Applied Biosystems). Primers and probes for real-time PCR were provided by Applied Biosystems. Assay IDs were Rn00565874_m1 (UCP3), Rn00565707_m1 (PPARס), Rn00690933_m1 (peptidylprolyl isomerase A, PPIA) and 4352931E ( $\beta$-actin). Amplification and detection were performed using the ABI PRISM 7300 sequence detection system (Applied Biosystems). All reactions were performed in duplicate. $B$-actin and PPIA were the two most stable normalization genes out of five tested using the GeNorm applet (39). Expression of the genes of interest was normalized by geometric averaging of the two internal control genes ( $ß$-actin and PPIA) using the GeNorm program. We calculated a normalization factor based on the expression levels of the 2 remaining endogenous controls. Data are expressed as foldchange in gene expression compared to the matched controls.

Statistical analyses. All results, except glucose and insulin concentrations during the IVGTT, were compared by using
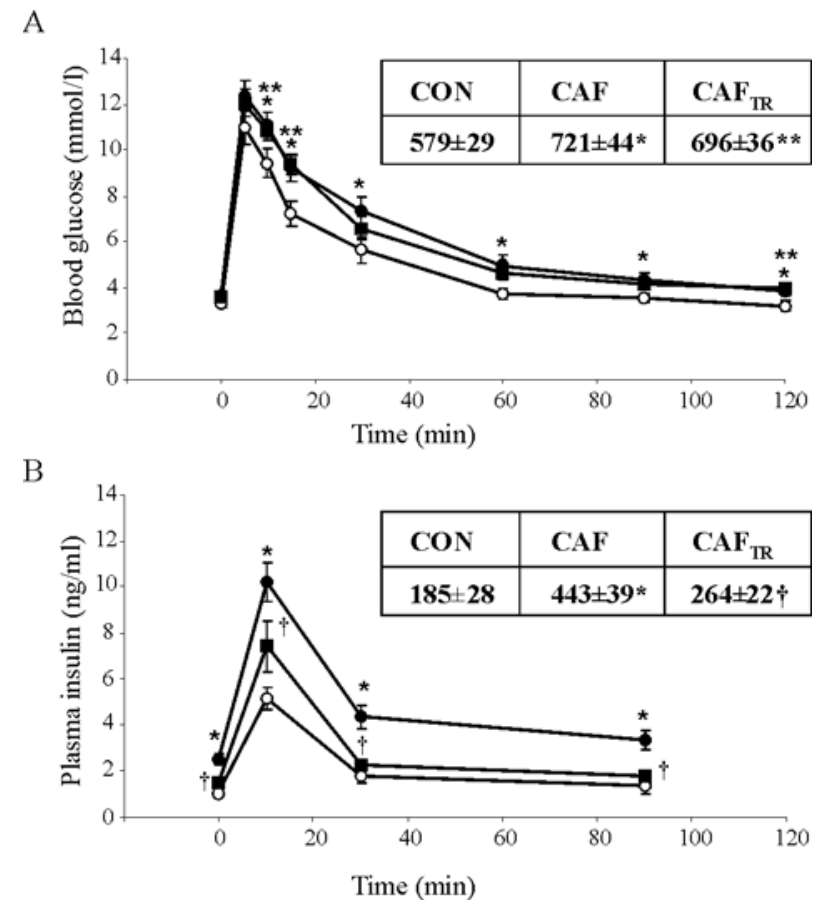

Figure 1. Effect of cafeteria-style diet and exercise training on blood glucose and plasma insulin during an intravenous glucose tolerance test (IVGTT). IVGTT was performed in control rats (CON, open circles, $n=12)$, cafeteriastyle diet fed rats in the absence (CAF, closed circles, $n=21$ ) and in the presence of training $\left(\mathrm{CAF}_{\mathrm{TR}}\right.$, squares, $\left.\mathrm{n}=15\right)$. A. Blood glucose concentrations during a 120-min IVGTT. B. Plasma insulin concentrations during a 120-min IVGTT. Inserts in figure A and B represent the area under the glucose and insulin curves, respectively. Values are mean \pm SE. ${ }^{*} \mathrm{p}<0.05 \mathrm{CAF}$ versus $\mathrm{CON}$, ${ }^{* *} \mathrm{p}<0.05 \mathrm{CAF}_{\mathrm{TR}}$ versus $\mathrm{CON},{ }^{\dagger} \mathrm{p}<0.05$ versus $\mathrm{CAF}$.

one-way ANOVA and followed by a planned contrast analysis (Statistica, Statsoft). Two-way ANOVA with repeated measures for time was used to analyze the glucose and insulin concentrations during the IVGTT. The relationship between variables was calculated using Pearson's correlation coefficient. A probability level ( $p) \leq 0.05$ was considered statistically significant. All data are expressed as means \pm SE.

\section{Results}

Characteristics of the dietary interventions and effect on body weight (Table II). Compared with CON, in CAF daily energy intake over the 12-week intervention period on average was $\sim 14 \%$ higher $(\mathrm{p}<0.001)$. In $\mathrm{CAF}_{\mathrm{TR}}$, energy intake was lower than in CAF $(\mathrm{p}<0.001)$, but not significantly different from CON $(\mathrm{p}=0.08)$. The higher energy intake in CAF, at the end of the intervention period resulted in $\sim 20 \%$ higher body weight gain $(305 \pm 10 \mathrm{~g})$ than in CON $(255 \pm 14 \mathrm{~g}, \mathrm{p}<0.001)$. Body weight gain in $\mathrm{CAF}_{\mathrm{TR}}(253 \pm 7 \mathrm{~g})$ was similar to $\mathrm{CON}$. Due to different diet compositions, intakes (g/day) of carbohydrates, fats and proteins also were different between groups (Table II). Compared with CON, CAF and $\mathrm{CAF}_{\mathrm{TR}}$ ingested $\sim 3$-fold more saturated fats $(\mathrm{p}<0.001)$ and 5 -fold greater amount of sugars $(\mathrm{p}<0.001)$. However, they ingested $35-40 \%$ less protein and $55-60 \%$ less starch $(\mathrm{p}<0.001)$.

Exercise training reverses cafeteria-style diet induced glucose intolerance and muscular insulin resistance. The 

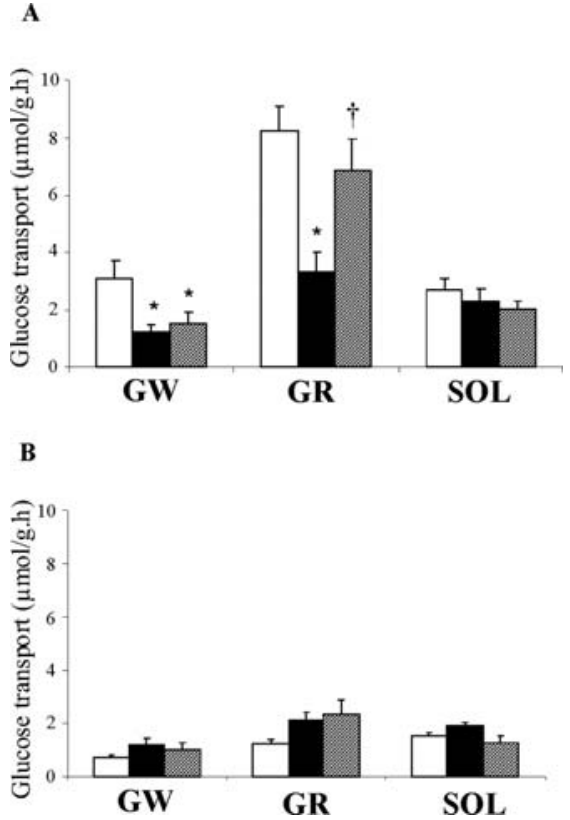

Figure 2. Effect of cafeteria-style diet and exercise training on 2-deoxy-D$2,6\left[{ }^{3} \mathrm{H}\right]$ glucose uptake in perfused hind limb muscles. The glucose uptake stimulated with $200 \mu \mathrm{U} / \mathrm{ml}$ insulin (panel A) and in the absence of insulin (panel B) during the hind limb perfusion was determined by measuring the 2-deoxy-D-2,6 $\left[{ }^{3} \mathrm{H}\right]$ glucose uptake in the perchloric acid extracts from white $(\mathrm{GW})$ and red gastrocnemius (GR) and soleus (SOL) muscles and corrected for extracellular space. The muscles were obtained from control rats (white bars) and rats receiving cafeteria-style diet in the absence (black bars) and presence of training interventions (striped bars) during the last 4 weeks of the 12 -week diet period. See Materials and methods section for further details. Values are expressed as mean \pm SE of $7-14$ observations. ${ }^{*} \mathrm{p}<0.05$ versus control group, ${ }^{\dagger} \mathrm{p}<0.05$ versus cafeteria-style diet fed rats.

effect of cafeteria-style diet and exercise training on wholebody glucose tolerance was studied using a 2-h intravenous glucose tolerance test (IVGTT; Fig. 1). At the end of the 12week intervention period, fasting blood glucose concentrations were similar between groups. However, fasting plasma insulin level was higher in CAF $(2.52 \pm 0.25 \mathrm{ng} / \mathrm{ml})$ than in CON $(0.90 \pm 0.14 \mathrm{ng} / \mathrm{ml} ; \mathrm{p}<0.001)$ or $\mathrm{CAF}_{\mathrm{TR}}(1.50 \pm 0.12 \mathrm{ng} / \mathrm{ml}$; $\mathrm{p}<0.001)$. Hence the fasted insulinogenic index was higher in CAF $(0.70 \pm 0.07 \mathrm{mg} / \mathrm{mol})$ than in CON $(0.29 \pm 0.04 \mathrm{mg} / \mathrm{mol}$; $\mathrm{p}<0.001)$ and $\mathrm{CAF}_{\mathrm{TR}}(0.42 \pm 0.04 \mathrm{mg} / \mathrm{mol} ; \mathrm{p}<0.001)$. During the IVGTT, blood glucose concentration in all groups rapidly increased from $\sim 3.5$ to $10-12 \mathrm{mmol} / \mathrm{l}$. However, compared with CON, in both CAF $(\mathrm{p}<0.01)$ and $\mathrm{CAF}_{\mathrm{TR}}(\mathrm{p}<0.05)$ the area under the glucose curve was greater. Plasma insulin increased markedly more upon glucose infusion in CAF than in CON, and throughout the IVGTT insulin concentrations consistently were 2 -3-fold higher in CAF ( $\mathrm{p}<0.001)$. In $\mathrm{CAF}_{\mathrm{TR}}$ plasma insulin was lower than in CAF $(\mathrm{p}<0.01)$, but was not significantly different from $\mathrm{CON}(\mathrm{p}=0.15)$. The differential glucose and insulin responses between groups also yielded lower Matsuda ISI in both CAF $(6.7 \pm 0.44 ; \mathrm{p}<0.001)$ and $\mathrm{CAF}_{\mathrm{TR}}(11.2 \pm 1.1 ; \mathrm{p}<0.01)$ than in $\mathrm{CON}(15.6 \pm 1.4)$. However, compared with CAF, ISI was significantly higher in $\mathrm{CAF}_{\mathrm{TR}}$ $(\mathrm{p}<0.001)$. Muscular insulin sensitivity was assessed as the rate of glucose transport in the perfused rat muscles, in the presence and absence of insulin. Compared with CON, in CAF glucose transport rate at $200 \mu \mathrm{U} / \mathrm{ml}$ perfusate insulin
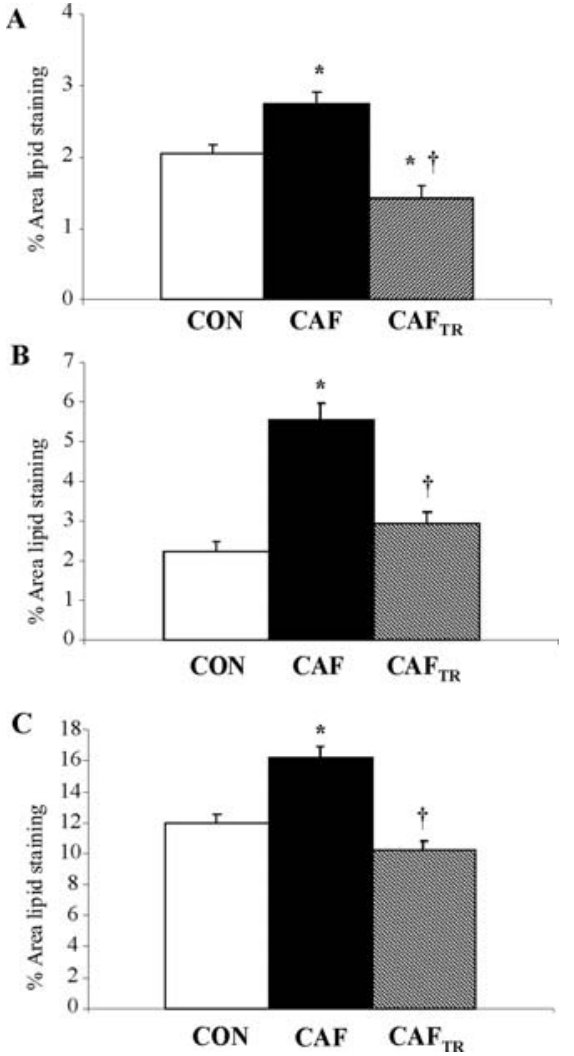

Figure 3. Effect of cafeteria-style diet and training intervention on intramyocellular lipid content. Intramyocellular lipid (IMCL) content was quantified by fluorescence microscopy on Oil-Red-O stained muscle crosssections in 3 different groups, control rats $(\mathrm{CON}$, white bar, $n=6)$, rats receiving cafeteria-style diet alone (CAF, black bar, $n=7$ ) or in the presence of training interventions $\left(\mathrm{CAF}_{\mathrm{TR}}\right.$, striped bars, $\left.\mathrm{n}=6\right)$. Panel $\mathrm{A}, \mathrm{B}$ and $\mathrm{C}$ represent IMCL content of type I fibers of soleus, type I fibers and type IIa fibers of EDL, respectively. Values are mean $\pm \mathrm{SE}$ and are expressed as percentage of the fiber area covered by fat droplets. ${ }^{*} \mathrm{p}<0.05$ compared with $\mathrm{CON}$ and, ${ }^{\dagger} \mathrm{p}<0.05$ compared with CAF.

concentration (Fig. 2, panel A) was significantly reduced by $\sim 60 \%$ in both red and white gastrocnemius muscles, but not in m. soleus ( $-15 \%$, n.s.). Exercise training largely reversed the impairment of insulin-stimulated glucose transport in red $(\mathrm{p}<0.01)$ but not white gastrocnemius muscle. Glucose transport rates in the absence of insulin (Fig. 2, panel B) were not significantly different between the three groups.

Exercise training reversed the increase in IMCL content due to cafeteria-style diet. Fiber-specific IMCL content was measured by ORO-staining in cross sections from $\mathrm{m}$. soleus and EDL (Fig. 3). IMCL content was $~ 6$-fold higher in type IIa fibers than in type I fibers in both $\mathrm{m}$. soleus or EDL. In either muscle or fiber type, the administration of cafeteriastyle diet substantially increased IMCL content. However, this increase was more prominent in EDL type I fibers $(+150 \%, \mathrm{p}<0.01)$ than in soleus type $\mathrm{I}(+36 \%, \mathrm{p}<0.01)$ and EDL type IIa fibers $(+33 \%, \mathrm{p}<0.01)$. Exercise training during the final 4 weeks of the intervention period, entirely negated the cafeteria-style diet-induced increment in IMCL content $(p<0.001)$. Thus, independent of muscle or fiber type, IMCL content in $\mathrm{CAF}_{\mathrm{TR}}$ was similar to $\mathrm{CON}$. Interestingly, over the different intervention groups, IMCL content in both type I fibers of EDL (Fig. 4, panel A) and soleus (Fig. 4, panel B) 
A

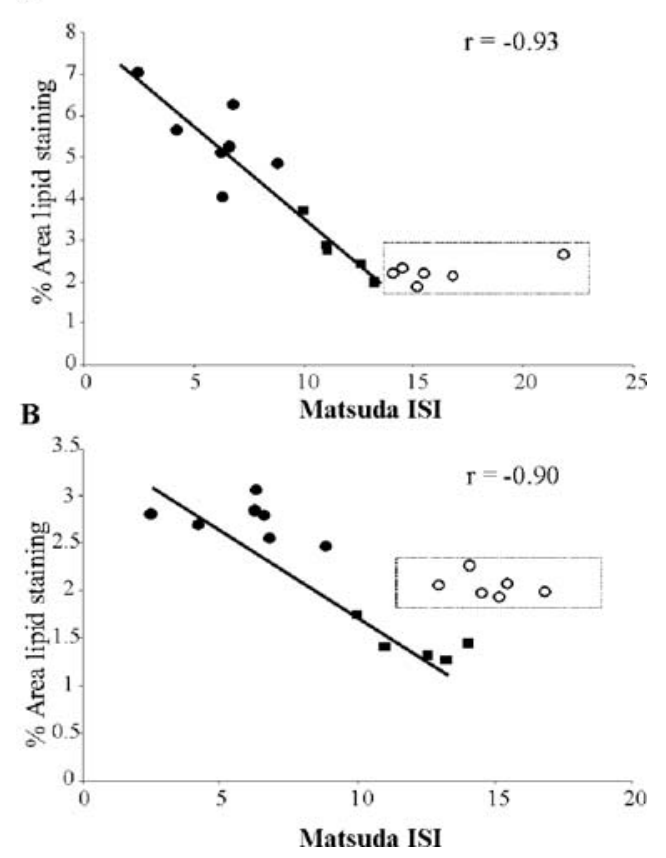

Figure 4. Correlation between the intramyocellular lipid content and Matsuda insulin sensitivity index. Correlation between the intramyocellular lipid content (IMCL) and the whole body Matsuda insulin sensitivity index (ISI) in the type I fibers of the EDL (panel A) and soleus (panel B) muscles was determined in rats fed a CAF diet alone (closed circles) or with training interventions during the last 4 weeks of the diet (squares). Control group (open circles) is surrounded by doted box. Values are mean \pm SE.

muscles was very closely negatively correlated with Matsuda ISI (soleus, $r=-0.93$; EDL, $r=-0.90 ; \mathrm{p}<0.05$ ). Similar but lower negative correlations existed for type IIa fibers in EDL $(\mathrm{r}=-0.52, \mathrm{p}<0.05)$.

Muscle UCP3 protein content was unaffected by either CAF diet or training. The protein content of UCP3 was assayed by Western blotting in both soleus and EDL muscles. In m. soleus values (arbitrary units, expressed relative to $\mathrm{CON}$, which was set at equal to 1 ) were $1.0 \pm 0.08,0.97 \pm 0.10$ and $1.07 \pm 0.12$ in $\mathrm{CON}$, $\mathrm{CAF}$ and $\mathrm{CAF}_{\mathrm{TR}}$, respectively. Corresponding values in $\mathrm{m}$. EDL were $1.00 \pm 0.22,0.79 \pm 0.27$ and $0.81 \pm 0.22$. There were no significant differences between the groups in either muscle type.

Effect of free fatty acids and glucose on muscle UCP3 gene expression. To further explore the effects of diet and training on muscle UCP3, we investigated the direct effects of high free fatty acid concentration ( $2 \mathrm{mM}$ palmitate), either in the presence or absence of high glucose level $(10 \mathrm{mM})$ on muscle UCP3 mRNA content in perfused rat muscles. Compared with control, in soleus, the addition of $2 \mathrm{mM}$ palmitate to the arterial perfusate, either in the absence $(\mathrm{p}<0.05)$ or presence $(\mathrm{p}<0.001)$ of glucose, increased UCP3 mRNA content $\sim 3$ fold. Similar effects were seen in the white gastrocnemius muscle (Fig. 5). Because PPAR $\delta$ has been implicated in regulation of UCP3 protein synthesis (40), we also looked at the effect of palmitate and glucose on PPAR $\delta$ mRNA content. However, relative values ranged between 0.61-1.0, with no significant differences between the experimental conditions $(\mathrm{p}>0.28)$.
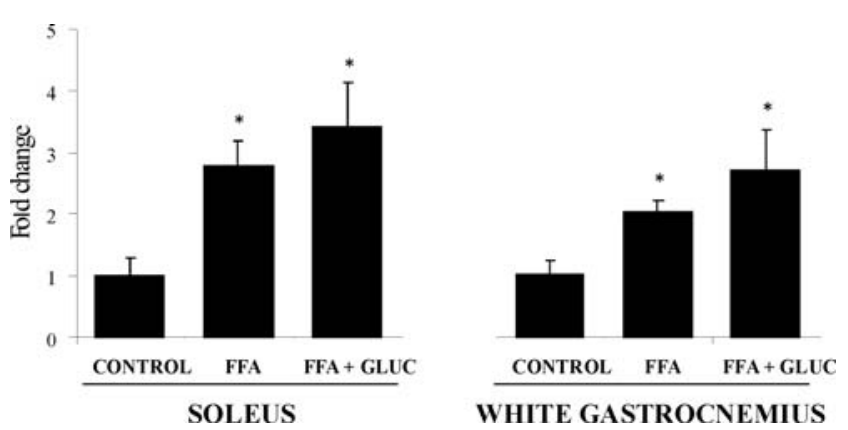

Figure 5. Effect of free fatty acids and glucose on UCP3 mRNA content in perfused rat muscles. Data are normalized to the geometric mean of $B$-actin and PPIA and expressed as mean \pm SE. Value in the control group was set at equal to one. Rat hind limbs were perfused in the absence (control) $(n=8)$ or presence of $2 \mathrm{mM}$ total palmitate (FFA) ( $\mathrm{n}=8)$ (or $15 \mathrm{nM}$ free), or $2 \mathrm{mM}$ palmitate $+10 \mathrm{mM}$ glucose (FFA + GLUC) $(\mathrm{n}=8)$, in soleus (left side) and white gastrocnemius (right side). See Materials and methods section for further details. ${ }^{*} \mathrm{p}<0.05$ versus control.

\section{Discussion}

As yet, the etiology of insulin resistance is not fully understood. Over recent years studies have provided evidence to indicate that abnormalities in skeletal muscle fat metabolism are implicated in the development of insulin resistance (41). Along this line, it is currently believed that fatty acid uptake into myocytes in excess of the capacity for intracellular disposal via either fatty acid oxidation (42) or triglyceride synthesis (43), leads to the formation of toxic lipid metabolites, which in turn may either directly or indirectly impair insulin action $(41,44)$. In this regard, some of us have previously postulated that UCP3 plays a role in maintenance of insulin action by exporting fatty acid anions or peroxidised fatty acids from the mitochondria, thereby preventing oxidative stressinduced mitochondrial damage and impairment of fat metabolism (45). In the current study we show that short-term hypercaloric sugar-rich diet in rats causes intramyocellular triglyceride content (IMCL) to markedly increase, which was associated with impaired peripheral insulin sensitivity and glucose tolerance. These detrimental effects were negated by exercise training, but occurred independent of regulation of muscle UCP3 protein expression.

The balance between fatty acid import and the capacity for fatty acid disposal in muscle cells, depends on environmental factors such as dietary fat load and degree of physical activity. Thus, fatty acid delivery to muscle cells is increased by fat-rich diet, whilst endurance exercise training upregulates the capacity for intramyocellular fat disposal via oxidation (46). There is also some preliminary evidence from cross-sectional studies in athletes to indicate that endurance training may increase the capacity for intramyocellular triglyceride synthesis $(9,47)$. In the current study we used a so-called 'cafeteria-style' diet to induce insulin resistance in rats. cafeteria-style diet enhances fat delivery to skeletal muscles both directly by increased dietary fat content and indirectly by sucrose-induced stimulation of hepatic lipogenesis $(30,48)$. In the current study, fasted serum triglyceride concentrations were increased $\sim 3$-fold within three weeks of cafeteria-style diet (data not shown). Moreover, due to its high palatability, cafeteria-style diet stimulates energy intake 
(Table II), which resulted in a $20 \%$ increase in body weight by the end of the study. The dietary intervention was also successful in producing a state of fat overload at the site of skeletal muscles because intra-myocellular lipid deposits significantly increased in both soleus and EDL muscles (Fig. 3). Simultaneously, whole-body glucose tolerance was impaired (Fig. 1), which was at least partly accounted for by deficient insulin-stimulated glucose uptake in skeletal musculature (Fig. 2). Compared with control rats, glucose transport in cafeteria rat muscles perfused in the presence of a submaximal insulin concentration $(200 \mu \mathrm{U} / \mathrm{ml})$ was markedly impaired in red gastrocnemius muscles, less in white gastrocnemius, but not in $\mathrm{m}$. soleus. This differential response between muscle types probably is at least partly explained by the greater capacity of rat slow-twitch fibers in an early stage of developing insulin resistance to compensate for emerging deficits in insulin action (49). Furthermore, short-term exercise training restored normal rate of insulin-stimulated glucose transport in red gastrocnemius muscles, but not in white gastrocnemius or $\mathrm{m}$. soleus. The failure of the latter two muscles to respond to the training intervention conceivably reflects the poor recruitment during swimming exercise in rats (50).

Interestingly, across the dietary and exercise interventions, intramyocellular lipid content closely negatively correlated with peripheral insulin sensitivity. Higher IMCL content was closely associated with lower insulin sensitivity index, an effect which was most prominent in EDL and soleus type I fibers (Fig. 4), which exhibited the largest variations in IMCL content due to the cafeteria-style diet and training. In fact, Fig. 4 indicates that at the low IMCL values measured in control rats $(\sim 2 \%$ area of ORO lipid staining), peripheral insulin sensitivity was independent of IMCL content. However, the cafeteria-style diet decreased the insulin sensitivity index proportionally to the increase in IMCL. Accordingly, exercise training during the final 4 weeks of the 12 -week dietary intervention increased the insulin sensitivity index proportionally to the decrease in IMCL. Therefore, our current findings corroborate earlier findings in both rodents (51) and humans (7) showing close associations between IMCL accumulation, due to an increased fat supply to muscles, and insulin sensitivity. A recent study by Holloway and co-workers have also demonstrated that as FFA transport in muscles from obese rats is increased by virtue of elevated circulating FFA concentration in conjunction with increased capacity for membrane FFA transport, the rate of intramyocellular triacylglycerol accumulation occurs at a much greater rate than the compensatory increase in the rate of mitochondrial fat oxidation (8). Accordingly, triacylglycerol synthesis rate from plasma-borne FFA's has been found to be increased in obese rabbits (52). Thus, and probably as long as intramyocellular fat stores are not overfilled, the bulk of excess fatty acids imported into the muscle cells during dietary fat challenge is converted to IMCL. This is compatible with the recent opinion that intracellular triacylglycerol acts as a metabolically inert reservoir for fatty acids within the muscle cells (43). Still, the preferential channelling of excess fatty acids toward triacylglycerol synthesis does not seem to prevent impairment of insulin efficiency. In this regard, the very close negative correlations between IMCL content and the insulin sensitivity index during the cafeteria-style diet and exercise training, indicate that within the range of IMCL contents observed here, the rate of formation of FFA metabolites presumed to be toxic to insulin action, such as diacylglycerol (14), ceramide (13) or peroxidised FFA's (9), is proportional to the degree of intracellular triacylglycerol accumulation, even in the presence of exercise training which obviously increases the rate of oxidative turnover of fatty acids from both intramyocellular and extramyocellular origin (53).

As indicated above, exaggerated fatty acid import into myocytes during episodes of dietary fat overload results in the formation fatty acid anions or peroxidised fatty acids, which in turn may impair insulin efficiency. In this regard, we have previously postulated that UCP3 plays a role in protecting muscle cells against oxidative mitochondrial damage by exporting the fatty acid anions and/or lipid peroxides formed by mitochondria (15-17). Support for such hypothesis comes from studies showing that UCP3 gene expression is upregulated in various conditions of exaggerated fat supply to skeletal muscles $(16,20,22)$. In the current study, during the cafeteria-style diet the rate of fatty acid supply to myocytes clearly overwhelmed the capacity for oxidative disposal, as evidenced by markedly elevated IMCL content (Fig. 3). Still, UCP3 content in any muscle type studied was affected neither by cafeteria-style diet, nor by exercise training, which negated the diet-induced increment in IMCL and conceivably also enhanced the rate of oxidative fat turnover (53). These observations clearly indicate that insulin resistance in rat muscles can develop independent of regulation at the site of mitochondrial UCP3 protein content. Until now, the evidence with regard to the possible role of UCP3 in the pathophysiology of 'fat-induced' insulin resistance remains somewhat equivocal. We and others have shown decreased UCP3 gene expression and protein content in subjects with impaired glucose tolerance and overt type 2 diabetes (26-28,54,55). Moreover, overexpression of UCP3 protected mice skeletal muscle against fat-induced insulin resistance (56). On the other hand a recent study in humans found similar UCP3 protein levels between type 2 diabetic patients and obese non-diabetic subjects (57) and another observation in mice show that transgenic changes in muscle UCP3 protein content did not alter muscular insulin sensitivity (58).

The cellular adaptations to changing dietary habits probably at least partly result from the cumulative effects of transient changes in gene expression due to food consumption. Along such rationale, intake of cafeteria food is likely to intermittently increase circulating FFA and glucose concentrations, and thereby regulate UCP3 gene expression. Therefore, we also studied the acute effects of high circulating FFA and glucose concentrations on UCP3 gene expression in the perfused muscles of control rats. Based on available literature data, we expected that simply increasing FFA supply to muscles should stimulate UCP3 gene transcription, and that simultaneous exposure to high glucose supply should enhance this effect by inhibition of FFA oxidation via the formation of malonylCoA (59). Accordingly, elevated FFA delivery to the hind limb muscles, in the form of a $2 \mathrm{mM}$ perfusate palmitate concentration, increased muscle UCP3 mRNA content about 3 -fold in both oxidative and glycolytic muscles, and this effect tended to be slightly enhanced (not significant) by the addition of a $10 \mathrm{mM}$ glucose concentration (Fig. 5). Nonetheless, 
12 weeks of cafeteria-style diet clearly failed to eventually increase muscle UCP3 protein content. The absence of a $\mathrm{UCP} 3$ response at the protein level probably is at least partly explained by the low absolute fat content of cafeteriastyle diet (Table I) in conjunction with the typical intermittent feeding pattern of rats (60). Thus, increments of circulating FFA and glucose levels due to food intake are probably minor. In fact, even high physiological concentrations of plasma FFA ( $2 \mathrm{mM}$ palmitate) and glucose within a 2-h time window caused only a minor increment in UCP3 mRNA content in the perfused muscles. Furthermore, the metabolic adaptation to cafeteria-style diet includes a consistently elevated plasma triglyceride level, but not increased FFA level (61). Therefore, our current data clearly indicate that dietinduced insulin-resistance in rats develops in the absence of regulation of muscle UCP3 protein content, indeed. However, we cannot exclude that UCP3 is implicated in the development of muscular insulin resistance due to consumption of diets containing substantially higher fat fractions than used here, as has been previously demonstrated $(16,20,22)$.

In conclusion, the current study clearly shows that shortterm administration of a sugar-rich hypercaloric diet in rats induces muscular insulin resistance and whole body glucose intolerance. This effect is largely negated by short-term exercise training. Changes in peripheral insulin sensitivity induced by diet and training are closely correlated with the concomitant changes in intramyocellular lipid level, but were independent of regulation at the site of muscle UCP3 content. The current findings support the opinion that short-term changes in intramyocellular lipid content in rats are implicated in the pathophysiology of insulin resistance. However, changes in UCP3 protein expression do not seem to play a key-role in the short-term development of insulin resistance in rat muscles.

\section{Acknowledgements}

The authors are grateful to Professor Erik Richter from Department of Exercise and Sport Sciences, University of Copenhagen, for the determination of glucose and insulin concentrations during IVGTT. Monique Ramaekers is acknowledged for her skilled technical performance. This study was supported by grants from the 'Onderzoeksraad K.U. Leuven' (grant \# OT04/45) and from the 'Fonds voor Wetenschappelijk Onderzoek Vlaanderen' (grant \# G.0233.05).

\section{References}

1. Ferrannini E, Bjorkman O, Reichard GA Jr, et al: The disposal of an oral glucose load in healthy subjects. A quantitative study. Diabetes 34: 580-588, 1985.

2. McAuley K and Mann J: Thematic review series: patient-oriented research. Nutritional determinants of insulin resistance. J Lipid Res 47: 1668-1676, 2006.

3. Petersen KF and Shulman GI: Etiology of insulin resistance. Am J Med 119: S10-S16, 2006.

4. Perseghin G, Scifo P, De Cobelli F, et al: Intramyocellular triglyceride content is a determinant of in vivo insulin resistance in humans: a $1 \mathrm{H}-13 \mathrm{C}$ nuclear magnetic resonance spectroscopy assessment in offspring of type 2 diabetic parents. Diabetes 48: 1600-1606, 1999.

5. Kuhlmann J, Neumann-Haefelin C, Belz U, et al: Intramyocellular lipid and insulin resistance: a longitudinal in vivo $1 \mathrm{H}$ spectroscopic study in Zucker diabetic fatty rats. Diabetes 52 : 138-144, 2003.
6. Jacob S, Machann J, Rett K, et al: Association of increased intramyocellular lipid content with insulin resistance in lean nondiabetic offspring of type 2 diabetic subjects. Diabetes 48 : 1113-1119, 1999.

7. Bachmann OP, Dahl DB, Brechtel K, et al: Effects of intravenous and dietary lipid challenge on intramyocellular lipid content and the relation with insulin sensitivity in humans. Diabetes 50: 2579-2584, 2001

8. Holloway GP, Benton C, Mullen KL, et al: In obese rat muscle transport of palmitate is increased and is channeled to triacylglycerol storage despite an increase in mitochondrial palmitate oxidation. Am J Physiol Endocrinol Metab 296: E738-E747, 2009.

9. Russell AP, Gastaldi G, Bobbioni-Harsch E, et al: Lipid peroxidation in skeletal muscle of obese as compared to endurance-trained humans: a case of good vs. bad lipids? FEBS Lett 551: 104-106, 2003.

10. Helge JW, Watt PW, Richter EA, Rennie MJ and Kiens B: Fat utilization during exercise: adaptation to a fat-rich diet increases utilization of plasma fatty acids and very low density lipoproteintriacylglycerol in humans. J Physiol 537: 1009-1020, 2001.

11. Turcotte LP, Richter EA and Kiens B: Increased plasma FFA uptake and oxidation during prolonged exercise in trained vs. untrained humans. Am J Physiol 262: E791-E799, 1992.

12. Moro C, Bajpeyi S and Smith SR: Determinants of intramyocellular triglyceride turnover: implications for insulin sensitivity. Am J Physiol Endocrinol Metab 294: E203-E213, 2008.

13. Summers SA: Ceramides in insulin resistance and lipotoxicity. Prog Lipid Res 45: 42-72, 2006.

14. Timmers S, Schrauwen P and de Vogel J: Muscular diacylglycerol metabolism and insulin resistance. Physiol Behav 94: 242-251, 2008.

15. Hoeks J, Hesselink MK and Schrauwen P: Involvement of UCP3 in mild uncoupling and lipotoxicity. Exp Gerontol 41: 658-662, 2006.

16. Schrauwen P, Hoppeler H, Billeter R, Bakker AH and Pendergast DR: Fiber type dependent upregulation of human skeletal muscle UCP2 and UCP3 mRNA expression by high-fat diet. Int J Obes Relat Metab Disord 25: 449-456, 2001.

17. Schrauwen P, Hoeks J, Schaart G, et al: Uncoupling protein 3 as a mitochondrial fatty acid anion exporter. FASEB J 17: 2272-2274, 2003.

18. Nabben $\mathrm{M}$ and Hoeks $\mathrm{J}$ : Mitochondrial uncoupling protein 3 and its role in cardiac- and skeletal muscle metabolism. Physiol Behav 94: 259-269, 2008.

19. Boss O, Samec S, Kuhne F, et al: Uncoupling protein-3 expression in rodent skeletal muscle is modulated by food intake but not by changes in environmental temperature. J Biol Chem 273: 5-8, 1998.

20. Chou CJ, Cha MC, Jung DW, Boozer CN, Hashim SA and Pi-Sunyer FX: High-fat diet feeding elevates skeletal muscle uncoupling protein 3 levels but not its activity in rats. Obes Res 9: 313-319, 2001.

21. De Bock K, Richter EA, Russell AP, et al: Exercise in the fasted state facilitates fibre type-specific intramyocellular lipid breakdown and stimulates glycogen resynthesis in humans. J Physiol 564: 649-660, 2005.

22. Hesselink MK, Greenhaff PL, Constantin-Teodosiu D, et al: Increased uncoupling protein 3 content does not affect mitochondrial function in human skeletal muscle in vivo. J Clin Invest 111: 479-486, 2003.

23. Millet L, Vidal H, Andreelli F, et al: Increased uncoupling protein-2 and -3 mRNA expression during fasting in obese and lean humans. J Clin Invest 100: 2665-2670, 1997.

24. Schrauwen P, Hesselink MK, Vaartjes I, et al: Effect of acute exercise on uncoupling protein 3 is a fat metabolism-mediated effect. Am J Physiol Endocrinol Metab 282: E11-E17, 2002.

25 . Weigle DS, Selfridge LE, Schwartz MW, et al: Elevated free fatty acids induce uncoupling protein 3 expression in muscle: a potential explanation for the effect of fasting. Diabetes 47: 298-302, 1998.

26. Kelley DE, He J, Menshikova EV and Ritov VB: Dysfunction of mitochondria in human skeletal muscle in type 2 diabetes. Diabetes 51: 2944-2950, 2002.

27. Mensink M, Hesselink MK, Borghouts LB, et al: Skeletal muscle uncoupling protein-3 restores upon intervention in the prediabetic and diabetic state: implications for diabetes pathogenesis? Diabetes Obes Metab 9: 594-596, 2007.

28. Schrauwen P, Mensink M, Schaart G, et al: Reduced skeletal muscle uncoupling protein-3 content in prediabetic subjects and type 2 diabetic patients: restoration by rosiglitazone treatment. J Clin Endocrinol Metab 91: 1520-1525, 2006. 
29. Koves TR, Ussher JR, Noland RC, et al: Mitochondrial overload and incomplete fatty acid oxidation contribute to skeletal muscle insulin resistance. Cell Metab 7: 45-56, 2008.

30. Petry CJ, Ozanne SE, Wang CL and Hales CN: Early protein restriction and obesity independently induce hypertension in 1-year-old rats. Clin Sci 93: 147-152, 1997.

31. Carmona A and Freedland RA: Comparison among the lipogenic potential of various substrates in rat hepatocytes: the differential effects of fructose-containing diets on hepatic lipogenesis. J Nutr 119: 1304-1310, 1989

32. Matsuda M and DeFronzo RA: Insulin sensitivity indices obtained from oral glucose tolerance testing: comparison with the euglycemic insulin clamp. Diabetes Care 22: 1462-1470, 1999.

33. Ruderman NB, Houghton CR and Hems R: Evaluation of the isolated perfused rat hindquarter for the study of muscle metabolism. Biochem J 124: 639-651, 1971.

34. Wojtaszewski JF, Hansen BF, Urso B and Richter EA: Wortmannin inhibits both insulin- and contraction-stimulated glucose uptake and transport in rat skeletal muscle. J Appl Physiol 81: 1501-1509, 1996.

35. Richieri GV, Anel A and Kleinfeld AM: Interactions of longchain fatty acids and albumin: determination of free fatty acid levels using the fluorescent probe ADIFAB. Biochemistry 32: 7574-7580, 1993.

36. Turcotte LP, Petry C, Kiens B and Richter EA: Contractioninduced increase in Vmax of palmitate uptake and oxidation in perfused skeletal muscle. J Appl Physiol 84: 1788-1794, 1998.

37. De Bock K, Derave W, Eijnde BO, et al: Effect of training in the fasted state on metabolic responses during exercise with carbohydrate intake. J Appl Physiol 104: 1045-1055, 2008.

38. Schrauwen P, Russell AP, Moonen-Kornips E, Boon N and Hesselink MK: Effect of 2 weeks of endurance training on uncoupling protein 3 content in untrained human subjects. Acta Physiol Scand 183: 273-280, 2005.

39. Vandesompele J, De Preter K, Pattyn F, et al: Accurate normalization of real-time quantitative RT-PCR data by geometric averaging of multiple internal control genes. Genome Biol 3: Research0034, 2002.

40. Villarroya F, Iglesias R and Giralt M: PPARs in the control of uncoupling proteins gene expression. PPAR Res 2007: 74364, 2007.

41. Kraegen EW and Cooney GJ: Free fatty acids and skeletal muscle insulin resistance. Curr Opin Lipidol 19: 235-241, 2008.

42. Bruce CR, Hoy AJ, Turner N, et al: Overexpression of carnitine palmitoyltransferase- 1 in skeletal muscle is sufficient to enhance fatty acid oxidation and improve high-fat diet-induced insulin resistance. Diabetes 58: 550-558, 2009.

43. Schenk S, Saberi M and Olefsky JM: Insulin sensitivity: modulation by nutrients and inflammation. J Clin Invest 118: 2992-3002, 2008.

44. Schrauwen P: High-fat diet, muscular lipotoxicity and insulin resistance. Proc Nutr Soc 66: 33-41, 2007.

45. Schrauwen $P$ and Hesselink MK: The role of uncoupling protein 3 in fatty acid metabolism: protection against lipotoxicity? Proc Nutr Soc 63: 287-292, 2004.
46. Schrauwen P, van Aggel-Leijssen DP, Hul G, et al: The effect of a 3-month low-intensity endurance training program on fat oxidation and acetyl-CoA carboxylase- 2 expression. Diabetes 51: 2220-2226, 2002 .

47. Goodpaster BH, He J, Watkins S and Kelley DE: Skeletal muscle lipid content and insulin resistance: evidence for a paradox in endurance-trained athletes. J Clin Endocrinol Metab 86: 5755-5761, 2001.

48. Chen YD, Coulston AM, Zhou MY, Hollenbeck CB and Reaven GM: Why do low-fat high-carbohydrate diets accentuate postprandial lipemia in patients with NIDDM? Diabetes Care 18: 10-16, 1995.

49. Bonen A, Tan MH and Watson-Wright WM: Insulin binding and glucose uptake differences in rodent skeletal muscles. Diabetes 30: 702-704, 1981.

50. Laughlin MH, Mohrman SJ and Armstrong RB: Muscular blood flow distribution patterns in the hindlimb of swimming rats. Am J Physiol 246: H398-H403, 1984.

51. Kuhlmann J, Neumann-Haefelin C, Belz U, Kramer W, Juretschke HP and Herling AW: Correlation between insulin resistance and intramyocellular lipid levels in rats. Magn Reson Med 53: 1275-1282, 2005.

52. Zhang XJ, Chinkes DL, Wu Z, Herndon DN and Wolfe RR: The synthetic rate of muscle triglyceride but not phospholipid is increased in obese rabbits. Metabolism (In press).

53. Kiens B: Skeletal muscle lipid metabolism in exercise and insulin resistance. Physiol Rev 86: 205-243, 2006.

54. Heilbronn LK, Gan SK, Turner N, Campbell LV and Chisholm DJ: Markers of mitochondrial biogenesis and metabolism are lower in overweight and obese insulin-resistant subjects. J Clin Endocrinol Metab 92: 1467-1473, 2007.

55. Patti ME, Butte AJ, Crunkhorn S, et al: Coordinated reduction of genes of oxidative metabolism in humans with insulin resistance and diabetes: Potential role of PGC1 and NRF1. Proc Natl Acad Sci USA 100: 8466-8471, 2003.

56. Choi CS, Fillmore JJ, Kim JK, et al: Overexpression of uncoupling protein 3 in skeletal muscle protects against fat-induced insulin resistance. J Clin Invest 117: 1995-2003, 2007.

57. Mogensen M, Sahlin K, Fernstrom M, et al: Mitochondrial respiration is decreased in skeletal muscle of patients with type 2 diabetes. Diabetes 56: 1592-1599, 2007.

58. Costford SR, Chaudhry SN, Crawford SA, Salkhordeh M and Harper ME: Long-term high-fat feeding induces greater fat storage in mice lacking UCP3. Am J Physiol Endocrinol Metab 295: E1018-E1024, 2008.

59. Elayan IM and Winder WW: Effect of glucose infusion on muscle malonyl-CoA during exercise. J Appl Physiol 70: 1495$1499,1991$.

60. Zorrilla EP, Inoue K, Fekete EM, Tabarin A, Valdez GR and Koob GF: Measuring meals: structure of prandial food and water intake of rats. Am J Physiol Regul Integr Comp Physiol 288: R1450-R1467, 2005.

61. Desai M, Byrne CD, Meeran K, Martenz ND, Bloom SR and Hales CN: Regulation of hepatic enzymes and insulin levels in offspring of rat dams fed a reduced-protein diet. Am J Physiol 273: G899-G904, 1997. 